\title{
Stage IV Fallopian Tube Cancer AJCC v8
}

National Cancer Institute

\section{Source}

National Cancer Institute. Stage IV Fallopian Tube Cancer A/CC v8. NCI Thesaurus. Code C139997.

Stage IV includes: Any T, Any N, M1: M1: Distant metastasis, including pleural effusion with positive cytology; liver or splenic parenchymal metastasis; metastasis to extraabdominal organs (including inguinal lymph nodes and lymph nodes outside the abdominal cavity); and transmural involvement of intestine. (from AJCC 8th Ed.) 